\title{
ANALISA PERBAIKAN PROFIL TEGANGAN SISTEM TENAGA LISTRIK SUMBAR MENGGUNAKAN KAPASITOR BANK DAN TAP TRANSFORMATOR
}

\author{
Akbar Abadi $^{1}$ dan Syafii $^{2}$ \\ ${ }^{1}$ Mahasiswa Program Studi S2 Teknik Elektro, Fakultas Teknik, Universitas Andalas \\ ${ }^{2}$ Jurusan Teknik Elektro, Fakultas Teknik, Universitas Andalas \\ e-mail: akbar_abadi@yahoo.co.id
}

\begin{abstract}
Abstrak - Evaluasi stabilitas tegangan perlu dilakukan untuk mendapatkan informasi performasi sistem penyaluran tenaga listrik. Perhitungan analisa aliran daya digunakan untuk menentukan parameterparameter penting sistem tenaga listrik dalam keadaan tunak. Suatu sistem tenaga listrik yang baik harus memiliki nilai tegangan yang tidak melebihi batas toleransi serta rugi-rugi daya yang kecil. Perbaikan profil tegangan dapat dilakukan dengan menggunakan peralatan pengatur tegangan, yaitu kapasitor bank dan tap transformator. Melalui simulasi menggunakan PowerWorld simulator akan diperoleh nilai dan lokasi kapasitor bank dan tap transformator yang tepat untuk memperbaiki performasi sistem. Sistem kelistrikan Sumbar digunakan dalam penelitian ini. Dari hasil simulasi, untuk kondisi awal sistem, terdapat beberapa bus yang mengalami drop tegangan dengan total rugi-rugi sistem sebesar 14,4 MW. Setelah penambahan kapasitor, tegangan sistem mengalami peningkatan yang signifikan sehingga tidak ada yang melewati nilai toleransi dan rugi-rugi sistem turun menjadi 14,1 MW. Sedangkan untuk pengaturan rasio tap transformator, tegangan sistem tidak mengalami perubahan yang begitu besar, kecuali pada sisi sekunder transformator bus yang diatur dengan rugi-rugi sistem hampir sama yaitu sebesar 14,4 MW. Untuk kasus penambahan kapasitor dan pengaturan rasio tap transformator sekaligus, tidak ada lagi drop tegangan yang melebihi dari $5 \%$ dan total rugi-rugi sistem turun menjadi 13,9 MW.
\end{abstract}

Kata Kunci : Stabilitas tegangan, Kapasitor bank, Tap transformator, Drop tegangan, dan Rugi-rugi sistem.

\begin{abstract}
Voltage stability evaluation is needed to get the information of electrical power distribution system performance. Power flow calculation is used to determine the important parameters of power system in a steady state. An electric power system must have voltage value that does not exceed the limits of tolerance and the power loss as well as small. The improvement of voltage profile can be done by using voltage-control equipments, such as capacitor banks and transformer tap. Through simulation using the PowerWorld simulator, the value and location of capacitor banks and transformers tap will obtained in order to improve system performace. Sumbar electrical system was used in this study. From the simulation results, for the initial condition of the system, there are several buses that have voltage drop with total system losses 14.4 MW. After capacitor added, the system voltage has increased significantly so that no one passed the value of tolerance and the losses in the system down to 14.1 MW. As for setting the ratio of tap transformer, voltage system did not change so much, except on the secondary side of the transformer bus arranged with system losses almost the same that equal to 14.4 MW. For the case of the addition of the capacitor and transformer tap settings in the same time, the voltage drop no longer exceeds 5\% and the total system losses decreased to $13.9 \mathrm{MW}$.
\end{abstract}

Keywords :Voltage stability, Capacitor bank, Tap transformator, Voltage drop, and System losses.

\section{PENDAHULUAN}

Listrik merupakan salah satu bentuk energi yang mempengaruhi hidup dan kehidupan manusia saat ini. Semakin berkembangnya ilmu pengetahuan menghasilkan penemuanpenemuan baru yang pada dasarnya membutuhkan listrik sebagai sumber energi. Dengan kata lain, semakin bertambah pula kebutuhan akan adanya listrik dalam kehidupan.
Kebutuhan di berbagai daerah dari waktu ke waktu selalu berbeda tergantung pada pemakaian listrik di daerah tersebut, sehingga penyediaan tenaga listrik dan alokasi pembangkit yang digunakan juga berbeda di daerah satu dan daerah lainnya [1]

Suatu sistem tenaga listrik terdiri dari banyak generator, transformator, elemen aktif dan pasif serta peralatan lainnya yang terinterkoneksi dalam jaringan transmisi antara beberapa buah 
atau bahkan beratus-ratus buah bus. Evaluasi kestabilan tegangan juga dilakukan untuk mendapatkan informasi mengenai kestabilan tegangan sistem dalam kondisi operasi tunak. Informasi ini sangat dibutuhkan guna mengevaluasi unjuk kerja sistem tenaga listrik dan menganalisis kondisi pembangkitan maupun pembebanan baik kondisi normal maupun darurat. Alasan lain diperlukan evaluasi kestabilan tegangan adalah untuk melihat performansi sistem tenaga listrik ketika sistem tenaga listrik tersebut diperluas dengan penambahan jaringan transmisi dan beban untuk memenuhi perkembangan kebutuhan tenaga listrik suatu daerah. Dengan evaluasi ini akan dijamin bahwa sistem tenaga yang baru dapat memenuhi kebutuhan listrik secara ekonomis, efisien dan aman.

Analisa aliran daya dalam sistem tenaga listrik untuk menentukan parameter-parameter sistem tenaga listrik [2]. Suatu sistem tenaga listrik yang baik harus memiliki nilai tegangan yang tidak melebihi batas toleransi serta rugirugi daya yang kecil. Nilai tegangan yang konstan akan memaksimalkan kinerja dari peralatan-peralatan listrik yang digunakan oleh konsumen. Sedangkan dengan rugi-rugi daya yang kecil akan menjaga pasokan daya listrik kepada konsumen sesuai dengan yang diinginkan serta dapat mengurangi kerugian finansial selama proses transmisi dan distribusi.

Proses perbaikan tegangan pada jaringan dapat dilakukan dengan menggunakan metode pengaturan tegangan yaitu dengan menggunakan kapasitor bank dan tap transformator. Untuk mendapatkan tegangan yang ideal, kita perlu kapasitor bank dan tap transformator. Sedangkan untuk mendapatkan nilai kapasitor bank dan tap transformator yang tepat, kita perlu menggunakan PowerWorld simulator. Pemasangan kapasitor diharapkan mampu menekan rugi-rugi atau susut energi pada sistem distribusi tegangan menengah serta memperbaiki kualitas daya listrik yang meliputi profil tegangan dan faktor daya yang diinginkan[3]. Aliran daya reaktif akan diatur sedemikian rupa sehingga rugi-rugi daya (losses) sistem akan menjadi seminimal mungkin. Dengan minimisasi rugi-rugi pada jaringan, profil tegangan bus akan dapat dijaga pada nilainilai yang diijinkan sehingga kontinuitas serta kualitas operasi sistem tenaga elektrik dapat senantiasa dipertahankan [4].

\section{TINJAUAN PUSTAKA}

\subsection{Sistem Tenaga Listrik}

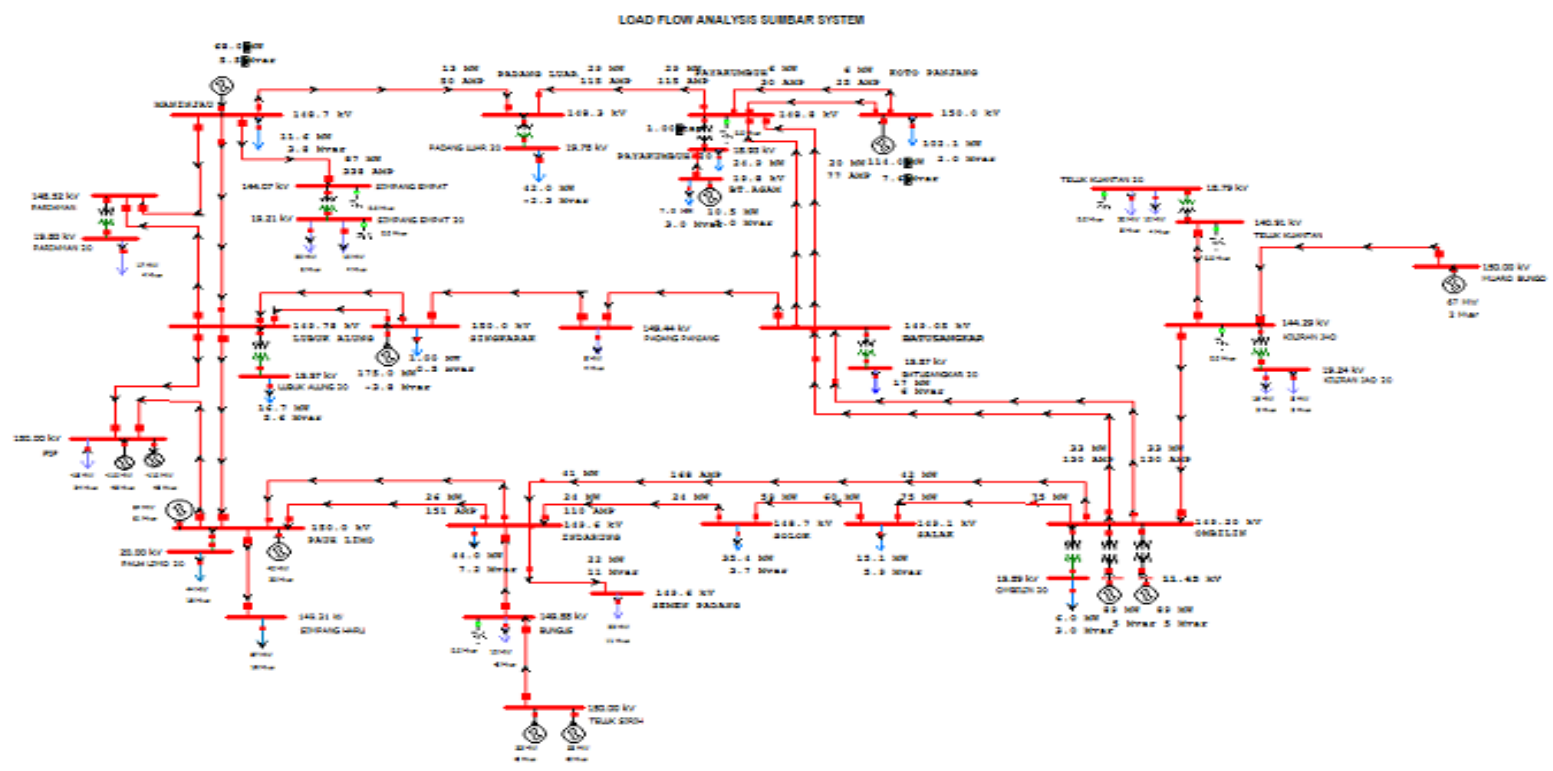

Gambar 1. Single Line Diagram Sistem Sumbar 
Sistem tenaga listrik terdiri dari 3 komponen utama yaitu pembangkit tenaga listrik, transmisi dan distribusi. Pada pusat listrik dilakukan pembangkitan tenaga dengan cara memanfaat generator sinkron [5]. Saluransaluran transmisi merupakan rantai penghubung antara pusat-pusat pembangkit listrik dan sistemsistem distribusi, dan melalui hubunganhubungan antar sistem dapat pula menuju ke sistem tenaga yang lain. Suatu sistem distribusi menghubungkan semua beban-beban yang terpisah antara satu dengan yang lainnya menggunakan saluran transmisi.

Kemampuan transmisi dari suatu saluran dengan tegangan tertentu tidak dapat ditetapkan dengan pasti, karena kemampuan ini masih tergantung lagi pada batasan-batasan (limit) thermal dari penghantar, jatuh tegangan (voltage drop) yang diperbolehkan, keterandalan, dan persyaratan-persyaratan kestabilan sistem (system stability), yaitu penjagaan bahwa mesinmesin pada sistem tersebut tetap berjalan serempak satu terhadap yang lain. Kebanyakan faktor- faktor ini masih tergantung pula pada panjangnya saluran [6]

Pada sistem multi-bus, penyelesaian aliran daya dengan metode persamaan aliran daya. Metode yang digunakan adalah Metode Newton-Raphson. Secara luas digunakan untuk permasalahan persamaan non-linear. Penyelesaian Persamaan ini menggunakan permasalahan yang linear dengan solusi pendekatan. Metode ini dapat diaplikasikan untuk satu persamaan atau beberapa Persamaan dengan beberapa variabel yang tidak diketahui.

Pada tahap awal dilakukan penomoran bus terhadap sistem yang akan dianalisis. Bus-bus yang terhubung dengan generator diberi nomor terlebih dahulu setelah itu penomoran bus dilanjutkan pada bus-bus beban, bus yang memiliki kapasitas pembangkit terbesar di pilih sebagai slack bus dan di beri nomor 1, untuk bus lain yang terhubung ke generator diberi nomor 3 sebagai bus pembangkit.

Perhitungan dimulai dengan membentuk impedansi jaringan $\left(\mathrm{Z}_{\mathrm{ij}}\right)$ dengan rumus :

$$
Z_{i j}=R_{i j}+j X_{j i}
$$

Kemudian impedansi jaringan dikonversi ke admitansi jaringan

$$
Y_{i j}=R_{i j}+j x_{j i}
$$

Selanjutnya maktriks admitansi bus [Y] dibentuk dengan komponen-komponen yang terdiri atas admitansi jaringan, kapasitansi saluran, dan perubahan tapping transformator. Kemudian matriks admitansi bus [Y] yang terbentuk dalam bentuk rectangular dirubah ke dalam bentuk polar. Dimana sebelumnya matriks admitansi bus [Y] tersebut dipisahkan menjadi komponen matriks [G] dan matriks [B].

Daya terjadwal pada setiap bus dihitung dengan rumus :

$$
\begin{aligned}
& \mathrm{P}_{\mathrm{i}}^{\mathrm{jd}}=\mathrm{P}_{\mathrm{Gi}}-\mathrm{P}_{\mathrm{Li}} \\
& \mathrm{Q}_{\mathrm{i}}{ }^{\mathrm{jd}}=\mathrm{Q}_{\mathrm{Gi}}-\mathrm{Q}_{\mathrm{Li}}
\end{aligned}
$$

Iterasi dimulai dengan memasang pencacah iterasi terlebih dahulu. Dalam proses iterasi dicari daya terhitung dengan rumus :

$$
\begin{aligned}
& \mathrm{P}_{\mathrm{i}}=\sum_{\mathrm{n}=1}^{\mathrm{N}}\left|\mathrm{Y}_{\mathrm{in}} \mathrm{V}_{\mathrm{i}} \mathrm{V}_{\mathrm{n}}\right| \cos \left(\theta_{\mathrm{in}}+\delta_{\mathrm{n}}-\delta_{\mathrm{i}}\right) \\
& \mathrm{Q}_{\mathrm{i}}=\sum_{\mathrm{n}=1}^{\mathrm{N}}\left|\mathrm{Y}_{\mathrm{in}} \mathrm{V}_{\mathrm{i}} \mathrm{V}_{\mathrm{n}}\right| \sin \left(\theta_{\mathrm{in}}+\delta_{\mathrm{n}}-\delta_{\mathrm{i}}\right)
\end{aligned}
$$

Mismatch power dihitung dengan persamaan :

$$
\begin{aligned}
& \Delta \mathrm{P}_{\mathrm{i}}=\frac{\mathrm{P}_{\mathrm{i}}^{\mathrm{jd}}-\mathrm{P}_{\mathrm{i}}^{\mathrm{hit}}}{\mathrm{V}_{\mathrm{i}}} \\
& \Delta \mathrm{Q}_{\mathrm{i}}=\frac{\mathrm{Q}_{\mathrm{i}}{ }^{\mathrm{jd}}-\mathrm{Q}_{\mathrm{i}}^{\mathrm{hit}}}{\mathrm{V}_{\mathrm{i}}}
\end{aligned}
$$

Setelah mismatch daya dihitung maka selanjutnya membentuk matriks jacobian :

$$
\left[\begin{array}{cccccc}
\frac{\partial P_{2}}{\partial \delta_{2}} & \ldots & \frac{\partial P_{2}}{\partial \delta_{n}} & \left|V_{2}\right| \frac{\partial P_{2}}{\partial\left|V_{2}\right|} & \ldots & \left|V_{n}\right| \frac{\partial P_{2}}{\partial\left|V_{n}\right|} \\
\vdots & H=J 11 & \vdots & \vdots & N=J 12 & \vdots \\
\frac{\partial P_{n}}{\partial \delta_{2}} & \ldots & \frac{\partial P_{n}}{\partial \delta_{n}} & \left|V_{2}\right| \frac{\partial P_{n}}{\partial\left|V_{2}\right|} & \ldots & \left|V_{n}\right| \frac{\partial P_{n}}{\partial\left|V_{n}\right|} \\
\frac{\partial Q_{2}}{\partial \delta_{2}} & \ldots & \frac{\partial Q_{2}}{\partial \delta_{n}} & \left|V_{2}\right| \frac{\partial Q_{2}}{\partial\left|V_{2}\right|} & \ldots & \left|V_{n}\right| \frac{\partial Q_{2}}{\partial\left|V_{n}\right|} \\
\vdots & M=J 21 & \vdots & \vdots & L=J 22 & \vdots \\
\frac{\partial Q_{n}}{\partial \delta_{2}} & \ldots & \frac{\partial Q_{n}}{\partial \delta_{n}} & \left|V_{2}\right| \frac{\partial Q_{n}}{\partial\left|V_{2}\right|} & \ldots & \left|V_{n}\right| \frac{\partial Q_{n}}{\partial\left|V_{n}\right|}
\end{array}\right]
$$


Matriks jacobian ini terdiri dari 4 submatriks yaitu submatriks $\mathrm{H}, \mathrm{N}, \mathrm{M}$ dan $\mathrm{L}$ atau dengan ekspresi yang lain J1 1, J12, J21, dan J22.

Untuk submatriks $\mathrm{J} 11$ atau $\mathrm{H}$ dihitung dengan rumus :

Untuk komponen luar diagonal

$$
\frac{\partial \mathrm{P}_{\mathrm{i}}}{\partial \delta_{\mathrm{j}}}=-\left|\mathrm{V}_{\mathrm{i}} \mathrm{V}_{\mathrm{j}} \mathrm{Y}_{\mathrm{ij}}\right| \sin \left(\theta_{\mathrm{ij}}+\delta_{\mathrm{j}}-\delta_{\mathrm{i}}\right)
$$

Komponen diagonal

$$
\frac{\partial \mathrm{P}_{\mathrm{i}}}{\partial \delta_{\mathrm{j}}}=\sum_{\mathrm{n}=1, \mathrm{n} \neq 1}^{\mathrm{N}}\left|\mathrm{V}_{\mathrm{i}} \mathrm{V}_{\mathrm{n}} \mathrm{Y}_{\mathrm{in}}\right| \sin \left(\theta_{\mathrm{in}}+\delta_{\mathrm{n}}-\delta_{\mathrm{i}}\right)
$$

Untuk submatriks $\mathrm{M}$ atau $\mathrm{J} 21$ dihitung dengan rumus :

Untuk komponen luar diagonal

$$
\frac{\partial \mathrm{P}_{\mathrm{i}}}{\partial \delta_{\mathrm{j}}}=-\left|\mathrm{V}_{\mathrm{i}} \mathrm{V}_{\mathrm{j}} \mathrm{Y}_{\mathrm{ij}}\right| \cos \left(\theta_{\mathrm{ij}}+\delta_{\mathrm{j}}-\delta_{\mathrm{i}}\right)
$$

Untuk komponen diagonal

$$
\frac{\partial Q_{i}}{\partial \delta_{i}}=\sum_{n=1, n \neq i}^{N}\left|V_{i} V_{j} Y_{i j}\right| \cos \left(\theta_{i j}+\delta_{j}-\delta_{i}\right)=\sum_{n=1, n \neq i}^{N} \frac{\partial Q_{i}}{\partial \delta n}
$$

Untuk submatriks $\mathrm{J} 12=\mathrm{N}$ dihitung dengan rumus :

Untuk komponen luar diagonal

$$
\left|\mathrm{V}_{\mathrm{j}}\right| \frac{\partial \mathrm{P}_{\mathrm{i}}}{\partial\left|\mathrm{V}_{\mathrm{j}}\right|}=\left|\mathrm{V}_{\mathrm{j}}\right|\left|\mathrm{V}_{\mathrm{i}} \mathrm{Y}_{\mathrm{ij}}\right| \cos \left(\theta_{\mathrm{ij}}+\delta_{\mathrm{j}}-\delta_{\mathrm{i}}\right)
$$

atau

$$
\left|\mathrm{V}_{\mathrm{j}}\right| \frac{\partial \mathrm{P}_{\mathrm{i}}}{\partial\left|\mathrm{V}_{\mathrm{j}}\right|}=-\frac{\partial \mathrm{Q}_{\mathrm{i}}}{\partial \delta_{\mathrm{j}}}
$$

Untuk komponen diagonal

$$
\left|\mathrm{V}_{\mathrm{i}}\right| \frac{\partial \mathrm{P}_{\mathrm{i}}}{\partial\left|\mathrm{V}_{\mathrm{i}}\right|}=\frac{\partial \mathrm{Q}_{\mathrm{i}}}{\partial \delta_{\mathrm{i}}}+2\left|\mathrm{~V}_{\mathrm{i}}\right|^{2} \mathrm{G}_{\mathrm{ii}}=\mathrm{P}_{\mathrm{i}}+\left|\mathrm{V}_{\mathrm{i}}\right|^{2} \mathrm{G}_{\mathrm{ii}}
$$

Untuk komponen submatiks L atau J22 dihitung dengan rumus :

Untuk komponen luar diagonal

$$
\left|\mathrm{V}_{\mathrm{j}}\right| \frac{\partial \mathrm{Q}_{\mathrm{i}}}{\partial\left|\mathrm{V}_{\mathrm{j}}\right|}=-\left|\mathrm{V}_{\mathrm{j}}\right|\left|\mathrm{V}_{\mathrm{i}} \mathrm{Y}_{\mathrm{ij}}\right| \sin \left(\theta_{\mathrm{ij}}+\delta_{\mathrm{j}}-\delta_{\mathrm{i}}\right)=\frac{\partial \mathrm{P}_{\mathrm{i}}}{\partial \delta_{\mathrm{j}}}
$$

Untuk komponen diagonal

$$
\left|\mathrm{V}_{\mathrm{i}}\right| \frac{\partial \mathrm{Q}_{\mathrm{i}}}{\partial\left|\mathrm{V}_{\mathrm{i}}\right|}=-\frac{\partial \mathrm{P}_{\mathrm{i}}}{\partial \delta_{\mathrm{i}}}-2\left|\mathrm{~V}_{\mathrm{i}}\right|^{2} \mathrm{~B}_{\mathrm{ii}}=\mathrm{Q}_{\mathrm{i}}-\left|\mathrm{V}_{\mathrm{i}}\right|^{2} \mathrm{~B}_{\mathrm{ii}}
$$

Setelah diperoleh harga dari masing-masing elemen pada submatriks jacobian, selanjutnya dibentuk matriks jacobian dengan menggabungkan keempat submatriks jacobian tersebut. Matriks jacobian [Jacobian] selanjutnya diinvers menjadi [Jacobian ${ }^{-1}$ dengan menggunakan dekomposisi LU.

Sudut fasa dan magnitude tegangan tiap bus yang baru dicari dengan menggunakan rumus :

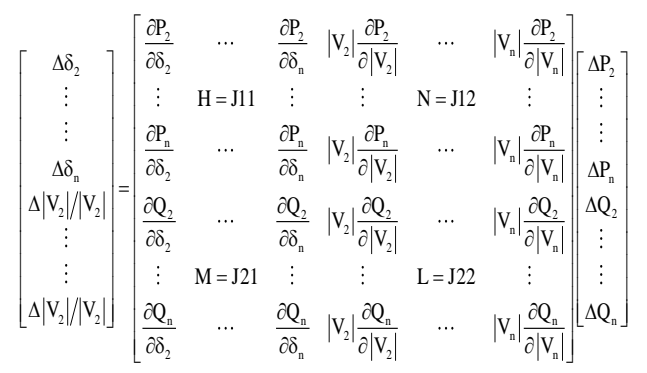

Hasil perkalian yang diperoleh selanjutnya dipisah-pisah menjadi bagian $\Delta \delta_{\mathrm{i}}$ dan $\frac{\Delta\left|\mathrm{V}_{\mathrm{i}}\right|}{\left|\mathrm{V}_{\mathrm{i}}\right|}$ :

$$
\begin{aligned}
& \Delta \delta_{\mathrm{i}}^{(\mathrm{k}+1)}=\delta_{\mathrm{i}}^{(\mathrm{k})}+\Delta \delta_{\mathrm{i}}^{(\mathrm{k})} \\
& \left|\mathrm{V}_{\mathrm{i}}\right|^{(\mathrm{k}+1)}=\left|\mathrm{V}_{\mathrm{i}}\right|^{(\mathrm{k})}+\Delta\left|\mathrm{V}_{\mathrm{i}}\right|^{(\mathrm{k})}=\left|\mathrm{V}_{\mathrm{i}}\right|^{(\mathrm{k})}\left(1+\frac{\Delta\left|\mathrm{V}_{\mathrm{i}}\right|^{(\mathrm{k})}}{\left|\mathrm{V}_{\mathrm{i}}\right|^{(\mathrm{k})}}\right)
\end{aligned}
$$

Daya pada slack bus dihitung setelah konvergensi tercapai, dengan rumus :

$$
\begin{aligned}
& \mathrm{P}_{\mathrm{i}}=\sum_{\mathrm{n}=1}^{\mathrm{N}}\left|\mathrm{Y}_{\mathrm{in}} \mathrm{V}_{\mathrm{i}} \mathrm{V}_{\mathrm{n}}\right| \cos \left(\theta_{\mathrm{in}}+\delta_{\mathrm{n}}-\delta_{\mathrm{i}}\right) \\
& \mathrm{Q}_{\mathrm{i}}=\sum_{\mathrm{n}=1}^{\mathrm{N}}\left|\mathrm{Y}_{\mathrm{in}} \mathrm{V}_{\mathrm{i}} \mathrm{V}_{\mathrm{n}}\right| \sin \left(\theta_{\mathrm{in}}+\delta_{\mathrm{n}}-\delta_{\mathrm{i}}\right)
\end{aligned}
$$

Selain itu daya reaktif pada bus PV (pembangkit) juga dihitung setelah konvergensi tercapai. Dengan rumus :

$$
\mathrm{Q}_{\mathrm{i}}=\sum_{\mathrm{n}=1}^{\mathrm{N}}\left|\mathrm{Y}_{\mathrm{in}} \mathrm{V}_{\mathrm{i}} \mathrm{V}_{\mathrm{n}}\right| \sin \left(\theta_{\mathrm{in}}+\delta_{\mathrm{n}}-\delta_{\mathrm{i}}\right)
$$


Aliran daya antar bus dihitung dengan rumus :

$$
\begin{gathered}
S_{i j}=V_{i}\left(V_{i j}^{*} Y_{i j}^{*}+V_{i}^{*} Y^{*} c_{i j}\right) \\
\text { atau } \\
P_{i j}-J Q_{i j}=V_{i}^{*}\left(V_{i}-V_{j}\right) Y_{i j}+V_{i}^{*} V_{i} Y c_{i j}
\end{gathered}
$$

Rugi-rugi daya antar bus dihitung dengan menggunakan rumus :

$$
\mathrm{S}_{\mathrm{ij}}(\text { losses })=\mathrm{S}_{\mathrm{ij}}+\mathrm{S}_{\mathrm{ji}}
$$

\subsection{Kompensasi Kapasitor Shunt}

Kapasitor shunt berguna sebagai sumber daya reaktif tambahan untuk mengkompensasi daya induktif akibat pembebanan dengan melakukan kompensasi daya reaktif, yang bertujuan untuk transportasi daya reaktif pada jaringan tenaga listrik dan menjaga agar profil tegangan selalu berada pada batas-batas yang diijinkan [7]. Pemasangan kapasitor shunt ini diharapkan akan dapat menurunkan rugi-rugi yang berarti penghematan energi listrik, peningkatan kualitas tegangan dan kualitas daya (power quality), serta penurunan arus listrik yang mengalir pada beban sehingga dapat menambah beban tanpa perlu menambah atau membangun saluran yang baru.

Kapasitor shunt mensuplai daya reaktif atau arus untuk menetralkan komponen keluaran antar fasa dari arus yang diperlukan oleh beban induktif.

\subsection{Transformator Tap (Tap Changer)}

Perbaikan tegangan dapat dilakukan dengan menggunakan metode pengaturan tegangan berupa penggunaan tap tranformator. Dengan menggunakan tap transformator kita dapat mengatur rasio lilitan primer dan sekunder transformator. Dengan demikian kita dapat mengatur tegangan keluaran transformator. Hal ini dapat dilihat pada persamaan berikut :

$$
\frac{V p}{V s}=\frac{N p}{N s}=a
$$

Keterangan:

$\mathrm{Vp}=$ Tegangan di sisi primer

Vs = Tegangan di sisi sekunder

$\mathrm{Np}=$ Jumlah lilitan primer

Ns $=$ Jumlah lilitan sekunder

$\mathrm{a}=$ Rasio lilitan
Tap transformator dapat digunakan di gardu induk maupun pada gardu distribusi tergantung dari perbaikan tegangan yang di inginkan. Proses perubahan tap transformator ada dua jenis, yaitu perubahan tap positif dan negatif. Biasanya nilai perubahan tap transformator menggunakan ukuran persen (\%), berkisaran dinilai 5\%. Perubahan tap positif dengan menambah jumlah lilitan di sisi sekunder, sedangkan tap negatif sebaliknya akan mengurangi jumlah lilitan di sisi sekunder. Tap transformator biasanya telah memiliki ukuran tap sendiri tergantung dari pabrik yang memproduksinya. Sehingga pengaturan tegangan dengan menggunakan tap transformator sifatnya terbatas dan tergantung dari jenis tap transformator yang digunakan. Semakin banyak level perubahan tap yang dimiliki oleh suatu transformator semakin baik pula proses pengaturan tegangan yang dapat dilakukan.

\section{METODOLOGI PENELITIAN}

Kasus yang dianalisa pada penelitian ini adalah sistem kelistrikan Sumbar. Data yang digunakan pada saat beban puncak (steady state) bulan November 2014 pada malam hari pukul 07.00 Wib. Pengolahan data dilakukan dengan memanfaatkan software PowerWorld dengan simulasi Load Flow. Ada beberapa tahap yang dilalui dalam pengolahan data yaitu:

1. Dengan penambahan kapasitor bank.

Dimana pada tahapan ini kita akan menggunakan kapasitor bank, melakukan perubahan nilai serta penempatan kapasitor bank yang digunakan dengan tepat sampai kita mendapatkan nilai tegangan yang diinginkan. Kapasitor bank ditempatkan pada bus-bus yang memiliki selisih tegangan yang lebih dari $5 \%$. Kapasitor bank dapat ditempatkan pada sisi primer dan sisi sekunder pada sistem. Dengan menggunakan PowerWorld simulasi kita dapat melihat penempatan, nilai kapasitor serta perubahan tegangan yang terjadi.

2. Dengan pengaturan rasio tap tranformator.

Pada metode ini dilakukan penggunaan tap transformator, dimana pada metode ini dilakukan dengan pengubahan rasio lilitan primer dan sekunder tranformator. Dengan demikian kita dapat mengatur tegangan keluaran tranformator. Perubahan ini 
dilakukan dengan menggunakan PowerWorld simulasi.

3. Dengan penambahan kapasitor bank dan pengaturan rasio tap transformator

Dengan metode ini, kita menggunakan kapasitor bank dan pengaturan rasio tap transformator secara bersamaan.

\section{HASIL DAN PEMBAHASAN}

Pada tabel 1 merupakan kondisi sistem kelistrikan Sumbar yang meliputi kondisi tegangan minimum dan rugi-rugi daya (losses) sistem.

Tabel 1. Kondisi sistem kelistrikan Sumbar

\begin{tabular}{|c|l|c|c|c|}
\hline No & \multicolumn{1}{|c|}{ Uraian tanpa } & $\begin{array}{c}\mathbf{V}_{\text {min }} \\
(\mathbf{k V})\end{array}$ & Bus & $\begin{array}{c}\text { Losses } \\
(\mathbf{M W})\end{array}$ \\
\hline 1 & $\begin{array}{l}\text { Sistem } \\
\text { kapasitor bank dan } \\
\text { Tap Transformator }\end{array}$ & $\begin{array}{c}\text { Teluk } \\
\text { Kuantan } \\
20\end{array}$ & 14,4 \\
\hline 2 & $\begin{array}{l}\text { Dengan } \\
\text { penambahan } \\
\text { kapasitor pada bus } \\
\text { Teluk Kuantan, bus } \\
\text { Payakumbuh 20 dan } \\
\text { bus Teluk Kuantan } \\
20\end{array}$ & 144,23 & $\begin{array}{c}\text { Simpang } \\
\text { Empat }\end{array}$ & 14,1 \\
\hline 3 & $\begin{array}{l}\text { Dengan pengaturan } \\
\text { rasio } \\
\text { transformator tap }\end{array}$ & 140,88 & $\begin{array}{c}\text { Teluk } \\
\text { Kuantan }\end{array}$ & 14,4 \\
\hline 4 & $\begin{array}{l}\text { Dengan } \\
\text { penambahan } \\
\text { kapasitor bank dan } \\
\text { pengaturan rasio tap } \\
\text { transformator }\end{array}$ & 146,26 & $\begin{array}{c}\text { Teluk } \\
\text { Kuantan }\end{array}$ & 13,9 \\
\hline
\end{tabular}

Dari tabel diatas dapat dilihat bahwa kondisi awal sistem tanpa kapasitor bank dan tap transformator, tegangan minimal yang terjadi terdapat pada bus Teluk Kuantan 20 yang mengalami jatuh tegangan sebesar 6,06\% sedangkan rugi-rugi daya yang terjadi sebesar 14,4 MW. Setelah dilakukan perbaikan tegangan dengan menambahkan 3 kapasitor yang ditempatkan pada bus Teluk Kuantan, bus Payakumbuh dan bus Teluk Kuantan 20. Tegangan pada sistem mengalami perbaikan tegangan yang cukup signifikan, sedangkan tegangan minimal yang terjadi terdapat pada bus
Simpang Empat dan rugi-rugi daya yang terjadi sebesar 14,1 MW. Ini berarti sistem mengalami penurunan rugi-rugi daya sebesar 0,3 $\mathrm{MW}$.

Perbaikan tegangan dengan metode pengaturan rasio tap transformator. Dimana pada metode ini, tegangan minimal pada sistem terjadi pada bus Teluk Kuantan dengan rugi-rugi daya sistem sebesar 14,4 MW. Dengan metode ini sistem tidak mengalami perubahan yang begitu besar, ini disebabkan karena pengaturan tegangan dengan menggunakan tap transformator sifatnya terbatas tergantung dari jenis tap transformator yang digunakan. Nilai perubahan rasio tap transformator menggunakan ukuran persen $(\%)$ berkisaran $5 \%$.

Untuk perbaikan tegangan dengan penambahan kapasitor bank dan pengaturan rasio tap transformator, tegangan minimal sistem terjadi pada bus Teluk Kuantan sedangkan rugirugi daya sistem yang terjadi sebesar 13,9 MW. Sistem yang pada awalnya terdapat bus-bus yang mengalami drop tegangan melebihi $5 \%$, setelah dilakukan perbaikan tegangan dengan menggunakan kapasitor bank dan pengaturan rasio tap transformator sistem mengalami perbaikan tegangan sehingga tegangan sistem lebih stabil. Tidak ada lagi drop tegangan yang melebihi dari $5 \%$. Sedangkan rugi-rugi daya yang terjadi mengalami penurunan sebesar 0,5 MW.

\section{KESIMPULAN}

Berdasarkan hasil analisa, maka dapat disimpulkan hal-hal sebagai berikut :

1. Perbaikan tegangan dengan penambahan kapasitor bank berdampak positif terhadap kenaikan tegangan pada sistem, dan penurunan rugi-rugi daya sistem.

2. Metode pengaturan rasio tap transformator memberikan dampak yang relatif kecil terhadap perbaikan tegangan sistem, kecuali pada sisi sekunder transformator bus yang diatur.

3. Dengan penggunaan kapasitor bank dan pengaturan rasio tap transformator secara bersamaan memberikan dampak yang signifikan terhadap kenaikan tegangan pada sistem dan rugi-rugi daya pada sistem mengalami penurunan yang lebih besar daripada hanya menggunakan kapasitor bank atau pengaturan rasio tap transformator. 


\section{DAFTAR PUSTAKA}

[1] Desriza, Ferdi. 2014. Peramalan Pemakaian Beban Transformator Daya Dengan Metode Autoregresive Integrated Moving Avarege (ARIMA) Di Gardu Induk Pauh Limo. Padang: Elektro Unand

[2] Emmy Hosea, Yusak Tanoto. 2004. Perbandingan Analisa Aliran Daya dengan Menggunakan Metode Algoritma Genetika dan Metode Newton-Raphson. Yogyakarta: Elektro Universitas Kristen Petra

[3] Dri, Adrianus. Meminimalkan Rugi-Rugi Pada Sistem Distribusi Tegangan Menengah Dengan Pemasangan Kapasitor. Tanjungpura: Elektro Universitas Tanjungpura

[4] Syarifil Anwar, Hadi Suyono dan Harry Soekotjo D. 2012. Optimisasi Penempatan SVC untuk Memperbaiki Profil Tegangan dengan Menggunakan Algoritma Genetika, Malang: Elektro Universitas Brawijaya

[5] Dwi Cahyanto, Restu. 2008. Studi Perbaikan Kualias Tegangan Dan RugiRugi Daya Pada Penyulang Pupur Dan Bedak Menggunakan Bank Kapasitor, Trafo Pengubah Tap Dan Penggantian Kabel Penyulang. Jakarta: Elektro UI

[6] Saadat, Hadi.1999. Power System Analysis. Michigan : Mc Graw-Hill Inc.

[7] Zuhal. 2000. Dasar Teknik Tenaga Listrik dan Elektronika Daya. Jakarta : Gramedia.

\section{Biodata Penulis}

Akbar Abadi, dilahirkan di Padang pada tahun 1984. Menyelesaikan pendidikan sarjana di jurusan Teknik Elektro Institut Teknologi Padang pada tahun 2009. Sekarang aktif sebagai teknisi di jurusan Teknik Elektro Fakultas teknik Unand. Saat ini tengah menempuh pendidikan jenjang Magister Teknik Elektro Fakultas Teknik Universitas Andalas Padang. 